\title{
The impact of green space and biodiversity on health
}

\author{
Hakkan Lai ${ }^{1}$, Emily J Flies ${ }^{2}$, Philip Weinstein ${ }^{3}$, and Alistair Woodward ${ }^{1 \star}$
}

Urban green spaces are associated with many health outcomes, but the mechanisms underlying these links remain unclear. One explanation is that biodiverse microbiomes in green spaces affect human health by modifying immune function. Our systematic review included studies that investigated the relationship between green space and either health or biodiversity. Reported effects of green space on health were generally positive, but $22 \%$ of the papers identified either no effect or negative effects. We also found that although green space was commonly associated with biodiversity, few green-space health studies simultaneously examined biodiversity. Overreliance on cross-sectional studies, various definitions of green space, and a lack of research in tropical and developing nations limit the conclusions that can be drawn. A better understanding of the biological aspects of contact with nature is required before city planners can optimize green spaces for health gains.

Front Ecol Environ 2019; 17(7): 383-390, doi:10.1002/fee.2077

The patterns of human exposure to nature have changed markedly over the past several decades, due principally to rapid urbanization. Seventy percent of the world's population resided in rural areas in the 1950s, but this fraction will shift to urban settings by 2050 , and relocation to cities is occurring most rapidly in developing countries (UN 2014). In many cities, densely packed high-rise buildings dominate, and little room remains for native flora or fauna (Gifford 2007). The competition for urban space results in a lack of exposure to natural environments (which we broadly refer to here as "green space"), and the implications for human health may be substantial.

\section{In a nutshell:}

- Today's rapidly urbanizing population is quickly losing access to green space and biodiversity

- Of the studies included in our review, $78 \%$ reported positive correlations between green space interaction and mental and physical health (the most frequently reported gains applied to mental health); only $5 \%$ reported negative associations

- Exposure to diverse microorganisms may help explain the effects of urban green space, but few of the studies in our review investigated potential biological mechanisms

- It is unclear to what extent research conducted to date may be generalized to tropical and developing countries; existing knowledge gaps must be filled to support effective green space planning in rapidly urbanizing non-Western settings

\footnotetext{
${ }^{1}$ School of Population Health, The University of Auckland, Auckland, New Zealand *(a.woodward@auckland.ac.nz); ${ }^{2}$ School of Biological Sciences, University of Tasmania, Hobart, Australia; ${ }^{3}$ School of Biological Sciences, University of Adelaide, Adelaide, Australia
}

Green spaces, as we have defined them, include many different habitats (Figure 1; Aronson et al. 2017), ranging from forests, conserved areas, parks, gardens, yards, and remnant patches of native vegetation to patches of vegetation within assemblages of modern or historically built environments. Green spaces contribute to the quality of urban life by providing basic ecosystem services such as air filtration, microclimate regulation, noise reduction, stormwater drainage, and sewage treatment, as well as opportunities for recreation (Bolund and Hunhammar 1999). Reported benefits to health resulting from exposure to green spaces include physical fitness and social cohesion (Hartig et al. 2014), improved mental health (Gascon et al. 2015), and reduced mortality (Gascon et al. 2016). Several studies have also documented negative effects, such as respiratory allergies (Andrusaityte et al. 2016) and injury (Bortolini et al. 2016). Explanations for these effects include psychological factors, sunlight exposure, and opportunities for exercise, but none of these proposed mechanisms explain the myriad "green space health effects" and the occasionally contradictory outcomes. Until the full range of mechanisms by which green spaces affect human health is better understood, scientists cannot predict with confidence the impacts that adding or removing a green space from an urban environment will have on public health.

One possible explanation of green-space health benefits is provided by the biodiversity hypothesis (Rook 2013; Kuo 2015; von Hertzen et al. 2015), which proposes that exposure to diverse microbiomes (communities of microbes such as bacteria, fungi, and protozoans) helps train the immune system to accurately distinguish dangerous from helpful bacteria, and immune modulation of this kind may affect a wide variety of health outcomes including cancer, depression, allergies, and auto-immune diseases. Some microbiomes are associated with natural environments (ie soils, plants, water), and exposure to diverse "environmental microbiomes" may contribute to the variety of microorgan- 


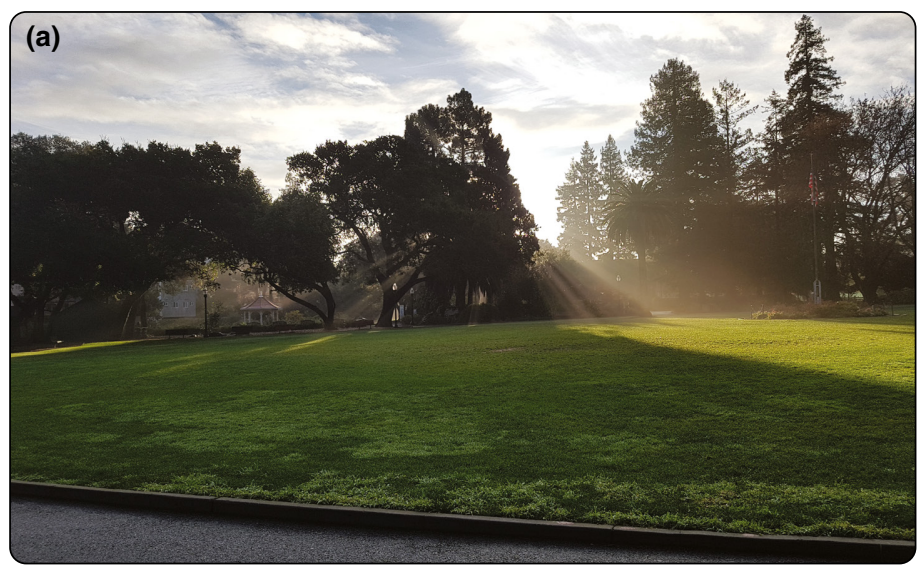

(b)

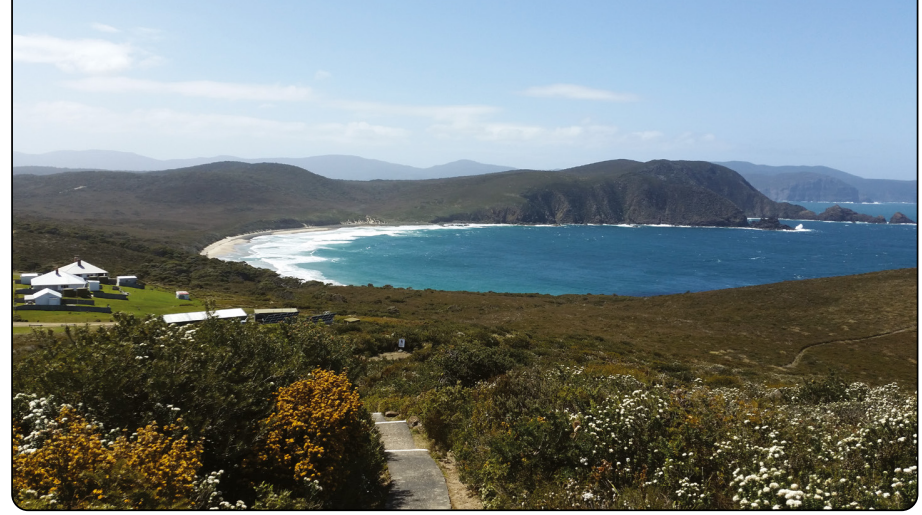

Figure 1. Biodiversity in an urban green space and in a natural area. (a) Urban green spaces, such as San Mateo Central Park in California, often lack biodiversity, whereas (b) natural areas outside cities, like that shown on Bruny Island in Tasmania, Australia, support a greater diversity of plants and animals. Although intuitive, these differences are seldom quantified, and therefore the role of biodiversity in contributing to human health outcomes is rarely examined.

isms in the human body. It is argued that exposures of this kind may protect against allergies (Hanski et al. 2012; Roukolainen et al. 2015), asthma (Ege et al. 2011), and upper respiratory tract infections (Fujimura et al. 2014) via alterations in immune function (expressed by changed levels of the immunoglobulin E [IgE] antibody, inflammatory cytokines, and activated T cells). However, little is known about the role that green space plays in contributing to the human microbiome, or the factors contributing to the diversity of the microbiome in green spaces. Scholarly literature at present fails to shed light on the effects of urban development on biodiversity in existing green spaces, and what this may mean for human health (Nelson and Forbes 2014; Nielsen et al. 2014).

Our objectives here were to systematically review the peerreviewed literature related to green space and public health to (1) summarize the components of mental and physical health affected by green space and the direction of the associated effects (eg positive, negative, neutral), (2) explore mechanisms proposed to account for green-space-related health benefits,
(3) examine the extent to which biodiversity has been considered as a component of health impacts, and (4) identify the most important existing gaps in knowledge that must be filled before urban planners can effectively design green spaces for the benefit of global urban health.

\section{Methods}

Our systematic review comprised four distinct stages: (1) identification, (2) screening, (3) eligibility assessment, and (4) summary and synthesis. These are discussed in turn below.

\section{Identification}

To identify relevant abstracts for potential inclusion within our review, we searched PubMed (www.ncbi.nlm.nih.gov/ pubmed) for articles published between January 2007 and March 2017 using a strategy developed from systematic testing (WebTable 1).

\section{Screening}

All abstracts were classified according to the following screening questions: (1) is "green space in urban area" one of the major research questions; (2) does the abstract relate to public health and green space; (3) does the abstract relate to biodiversity and green space; (4) what is the direction of evidence on green space and public health; and (5) what is the direction of evidence on biodiversity and public health? Other information considered in the screening process included study design, sample size, population, outcomes, green space variables, and the strength of associations.

\section{Eligibility assessment}

To improve interpretations of the abstracts and reduce misclassification errors, we sorted the abstracts according to how they related to the screening questions. Abstracts were divided into two groups based on answers to the questions about relevance to green space and public health (GSH) and to green space, health, and biodiversity (GSHB). Two additional groups of abstracts that were not directly related to public health, referred to as green space and biodiversity (GSB) and green space (GS) (WebPanel 1), were classified but excluded in the summary and synthesis stage. Full-text manuscripts were retrieved for papers in all four groups; abstracts that were not relevant to urban green space were excluded from the present review.

\section{Summary and synthesis}

To provide quantitative and qualitative information on the scope of the screened literature (described above), we summarized all papers based on study design, topic, directions of health effect, categories of health outcomes, and the plausible biomedical and biodiversity mechanisms. We also identified evident research gaps relating to green space and 
public health, and highlighted studies that included a component on biodiversity.

\section{Results}

As of 7 Jun 2017, 1336 abstracts were identified through our systematic search (WebTable 2). About $72 \%$ of the returned abstracts were not relevant to green space, indicating the false positive rate of the search strategy (Figure 2); in total, 275 of the 1336 abstracts (20.6\%) were relevant to our topic (the health effects of green space and biodiversity) and therefore examined more closely.

Of the papers that explored connections between green space and public health $(n=230)$, almost all applied epidemiological

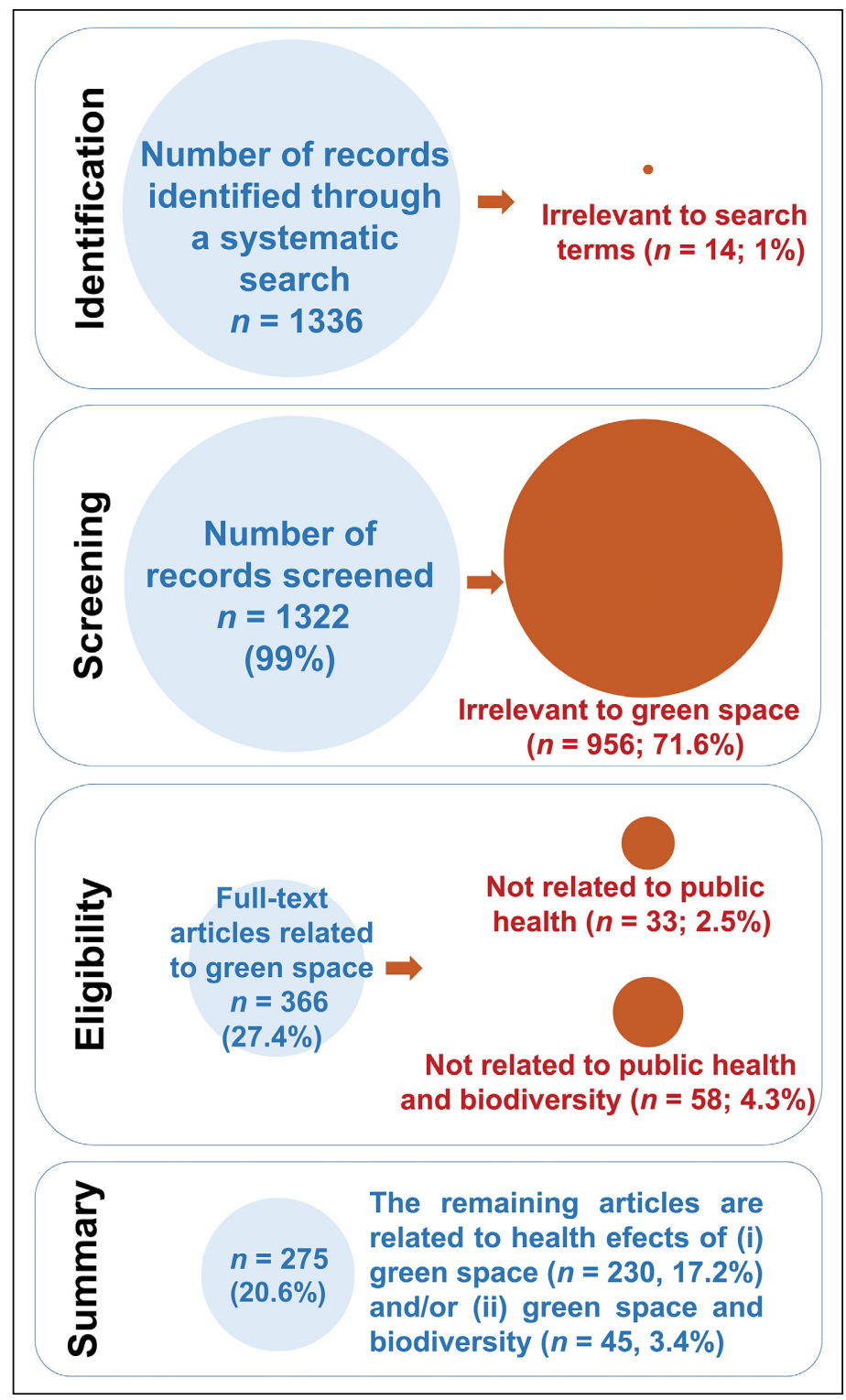

Figure 2. Search strategy and papers included and excluded (number and percent) at each stage. More details are available in WebPanel 1; a complete list of the papers and their classification is provided in WebTable 2. Size of each circle is relative to $n$. methods (WebPanel 2), and roughly two-thirds were observational studies (Figure 3). Some observational studies $(n=21)$ used cohort, longitudinal, case-crossover, and timeseries study designs, whereas others $(n=17)$ included randomized controlled trials, intervention, or experimental approaches. The papers that examined biodiversity in addition to green space and health $(n=45)$ were mostly reviews, and constituted what we describe as "biodiversity" studies (observational studies of biodiversity in urban green spaces with commentary on relevant health effects). Many of these studies focused on biodiversity or green space in association with either a natural agent (eg wild birds, wild boars, proteobacteria, arthropods [including ticks], bioaerosols, pollen) or an anthropogenic agent (eg dust, particulate pollutants, food waste). Health outcomes included lung cancer, cardiorespiratory disease, mental health, allergies, and immune system disorders (WebPanel 1). Overall, in the reviewed papers, cross-sectional studies were the most common category of research (48\%), followed by reviews (19\%) and cohort/longitudinal studies (7\%) (Figure 3).

Most quantitative studies of the health effects of green space ( $n=173,87 \%$ ) reported protective effects (Figure 4). Five studies $(2.5 \%)$ demonstrated both positive and negative effects on perceived health (Mitchell and Popham 2007), obesity (Dadvand et al. 2014; Burgoine et al. 2015), and allergies (Dadvand et al. 2014; Fuertes et al. 2014; Carlsten and Rider 2017). One (0.5\%) found optimal protective effects on mental health following moderate exposure to green space (AstellBurt et al. 2014a); 14 studies (7\%) did not show significant statistical associations between health and green space; and six studies (3\%) described negative associations, including increases in mortality risk (Richardson et al. 2012), skin cancer (Astell-Burt et al. 2014b) and overall cancer risk (Zhang et al. 2016), asthma (Andrusaityte et al. 2016), and injury (Bortolini et al. 2016), as well as a reduction in physical-activity-based commuting (Maki-Opas et al. 2016). The most commonly reported clinical outcomes were mental, neurological, and behavioral (20\%), while the most common non-clinical outcome was physical activity (18\%; WebTable 3). Other frequently reported outcomes were obesity/overweight (9\%) and self-perceived health (8\%), followed by mortality (6\%), cardiovascular health (5\%), and metabolic health (4\%).

Several review papers (WebTable 4) have hypothesized that exposure to microbial biodiversity may benefit immunoregulatory functions (Rook 2013; Rook et al. 2014), and that transmission of pathogens may occur less rapidly in biologically complex green areas (Rook et al. 2014). One crosssectional study (Ruokolainen et al. 2015) concluded that microbial biodiversity was a plausible explanation for associations observed between green space and health, and another study (Wolf et al. 2017) experimentally connected microbial diversity to mental health. We found no experimental studies that focused on microbial biodiversity and physical health outcomes.

The papers reviewed offer mechanisms to explain green space effects, including cognitive restoration, stress reduction, 


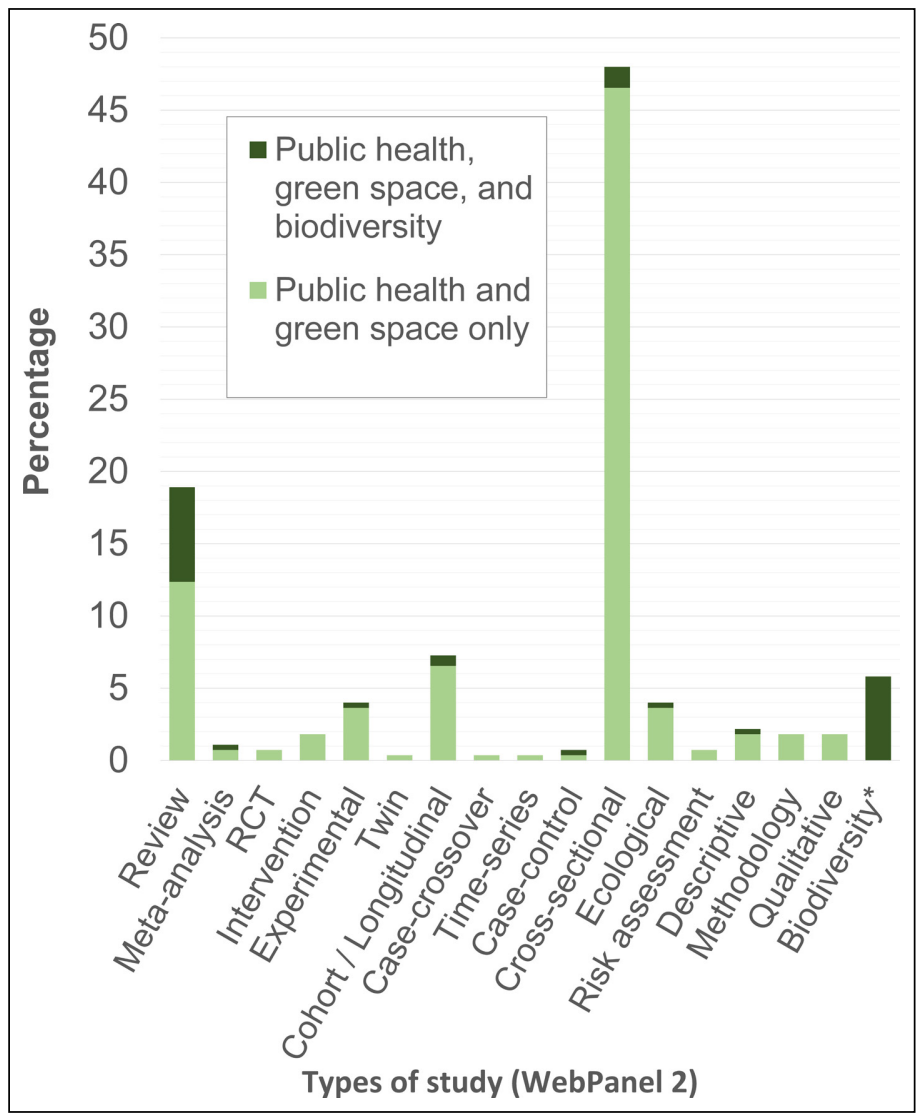

Figure 3. The proportion of abstracts $(n=275)$ according to epidemiological study design and classification (WebPanel 2). The asterisk indicates the exception of papers using methods for studying non-human species rather than using epidemiological methods. $\mathrm{RCT}=$ randomized controlled trial.

low levels of air pollution, microclimate regulation, and promotion of physical activity and social interaction (WebTable 4). Two studies (Astell-Burt et al. 2014c; Halonen et al. 2014) proposed that other mechanisms could account for the direct health effects of green space besides those affecting lifestyle choices. Two intervention studies (Aspinall et al. 2015; South et al. 2015) specifically tested cognitive restoration and stress response mechanisms.

Evidence of health effects was demonstrated in studies in 23 different countries (WebPanel 1), most of which were highly developed Western nations (with a Human Development Index $[\mathrm{HDI}] \geq 0.80$ ); no studies exploring the green space health effects were found for medium developed (HDI: 0.55-0.7) or less developed (HDI < 0.55) countries, and very few studies focused on countries in Africa, Asia, and Central and South America.

\section{Discussion}

The number of papers exploring connections between human health and green space or between human health and biodiversity has multiplied in recent years, stimulated in part by the paired rise in urban populations and certain chronic inflammatory diseases. In general, the health of urban residents is positively related to exposure to green space, but this relationship is not universal and there are occasionally negative effects. The results of recent studies focusing on the characteristics of health-advancing green space suggest that local biodiversity - and particularly microbial diversity - may be an important factor; however, we did not identify any experimental or intervention studies that tested this hypothesis directly.

\section{The health effects of green space}

The health outcomes most often examined with respect to green space, and the ones examined with greatest rigor, are mental/neurological/emotional health effects and levels of physical activity (WebTable 3). For these categories, there are relatively clear and intuitive links to green space. Most studies are correlative or observational (cross-sectional, ecological) but several probed more deeply, exploring mechanistic connections; for example, one study found that green space positively impacted cognition by altering brain-wave patterns (Aspinall et al. 2015), whereas another demonstrated positive effects of green space due to reduced exposure to trafficinduced air pollution (Dadvand et al. 2015). Promotion of physical activity and social interaction by green space (Triguero-Mas et al. 2015) has been shown to reduce perceived stress levels, as well as to modify relevant physiological variables like heart rate (South et al. 2015).

Almost $90 \%$ of the associations between green space and health identified in our literature review were positive (that is, exposure to green space was linked with health gain). Only $5 \%$ of the studies showed negative impacts of green space interaction (Figure 4). In some instances, green space had both positive and negative effects, such as with allergies (Dadvand et al. 2014; Fuertes et al. 2014; Carlsten and Rider 2017), obesity (Dadvand et al. 2014; Burgoine et al. 2015), and mortality (Richardson et al. 2012; Gascon et al. 2016).

\section{Inter-study discrepancies}

One possible explanation for conflicting positive and negative health effects is that the characteristics of green space differ from one study to another. Wheeler et al. (2015), for instance, reported that (apart from the estuaries landcover type) certain types of forests, agricultural lands, grasslands, and coastal lands were positively associated with the prevalence of good health and negatively associated with self-reported bad health in census data. In the papers considered in our review, some included many forms of urban green space (eg parks, lawns, golf courses, woodlands, wetlands, other vegetated areas; Richardson et al. 2012), whereas others were more limited, including for example forest and agricultural lands but not parks and grasslands (Ruokolainen et al. 2015). 
Other explanations for the variety of findings include unmeasured factors such as size and connectivity of urban green space (Lepczyk et al. 2017), human land-use patterns and development (Nelson and Forbes 2014), and the varying scales of the analyses (Richardson et al. 2012; Demuzere et al. 2014; Gascon et al. 2016). Some other potentially relevant biotic attributes of green space are rarely measured, such as the presence of invasive species as habitat homogenizing agents (Qian and Ricklefs 2007), the volume of understory habitats (Threlfall et al. 2017), and, notably, the level and composition of biodiversity. Moreover, green space was reported at widely different spatial resolutions, ranging from $5 \mathrm{~m}$ (Dadvand et al. 2015) to almost $10 \mathrm{~km}$ (WebPanel 1). Many studies used the normalized difference vegetation index (NDVI) (eg Dadvand et al. 2014, 2015; Triguero-Mas et al. 2015) to grade green spaces, while others relied on measures such as the leaf area index (Piao et al. 2015) or land-cover classifications (Richardson et al. 2012). This lack of a standardized approach to characterizing green space complicates direct comparisons between studies and understanding contradictory effects on health. If specific green space characteristics such as biodiversity, size, or connectivity can be directly tied to health metrics, then green space quality can be reported in a comparable fashion across studies, the results of which could be used to inform policy on how best to incorporate green space into urban design (Flies et al. 2017).

\section{The role of biodiversity}

Our review suggests that biodiversity plays a key role in the green space-health connection, but clear evidence of this relationship is lacking in the scientific literature. To date, most of the papers that have focused on the role of biodiversity or included a biodiversity component are commentaries and thought pieces (Figure 3). There are exceptions, however. One cross-sectional study of children demonstrated a relationship between green space, skin microbial biodiversity, and allergic sensitization (when the immune system is primed so that even minor exposure to an otherwise harmless substance leads to an allergic reaction) (Ruokolainen et al. 2015). Green space was associated with greater microbial diversity on the skin and reduced levels of allergic disease. However, this particular study excluded parks and grasslands in its classification of "green space", and it would be worth extending this research to include the types of green space that urbanites are most likely to be exposed to. Two other studies found associations between biodiversity and health, although it is unclear what the underlying mechanisms might be (Donovan et al. 2013; Wheeler et al. 2015). These findings are consistent with the "biodiversity" and "old friends" hypotheses (Hanski et al. 2012; Rook et al. 2014; von Hertzen et al. 2015), which propose that a greater diversity of microbes, especially with regard to those with which humans have co-evolved (ie "old friends"), helps to train and modulate the human immune system.

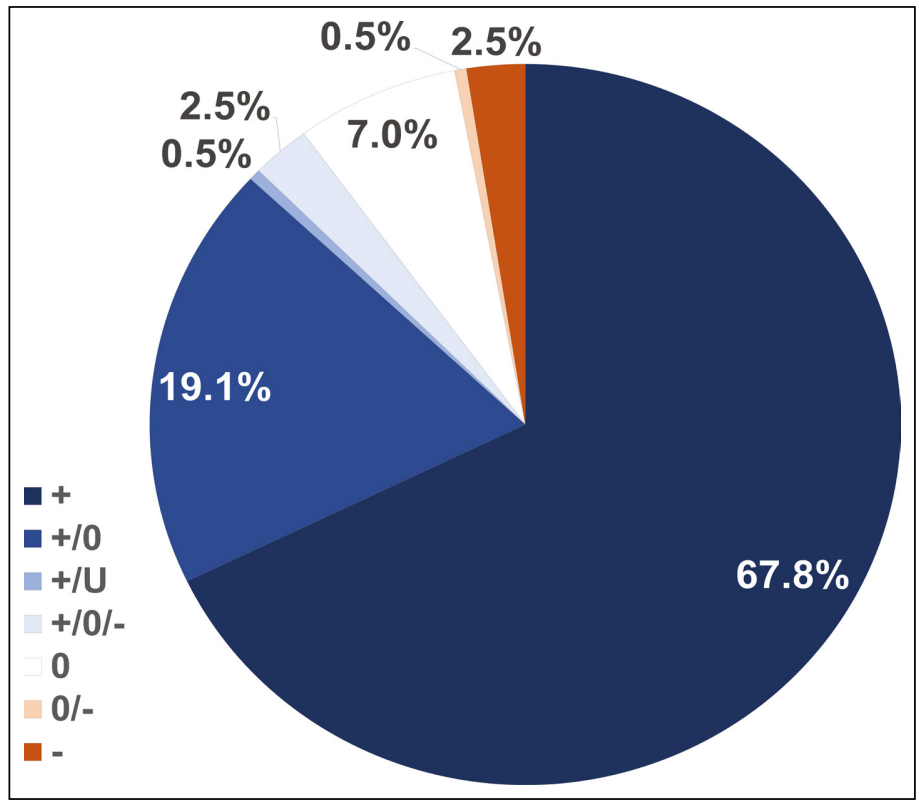

Figure 4. Findings of papers exploring the health impacts of green space $(n=199)$. Directions of association on health: + (positively associated, alpha $\leq 0.05$ ), - (negatively associated, alpha $\leq 0.05$ ), 0 (no association, alpha $>0.05$ ), and $U$ (patterns/indications of a U-shaped dose-response relationship, alpha $\leq 0.05$ ). Thirty-one studies were excluded because they lacked quantitative study designs (eg reviews; methodological or descriptive studies).

Most of the evidence for the relationship between biodiversity and health derives from epidemiological and clinical studies in other disciplines. For example, it is well established that children exposed to farm environments or farm animals (Riedler et al. 2001) are less likely to develop allergies or inflammatory conditions. Children who live on farms appear to be exposed to diverse environmental microbiomes, which reduce allergic and inflammatory responses (Ege et al. 2011). Animal studies provide some evidential support; for instance, microbial communities in mice (Cahenzli et al. 2013) and pigs (Mulder et al. 2009) are altered when these animals are raised in sterile settings (theoretically similar to developed urban environments), and they tend to have higher levels of inflammation and allergies. Green spaces potentially offer the urban equivalent of the microbial exposure that farms and animals provide.

The "old friends" and "biodiversity" hypotheses warrant further exploration in relation to urban green space health benefits. The rapidly developing fields of amplicon sequencing, metagenomics, and metabolomics are facilitating the functional and genetic characterization of environmental and human microbial communities. Pairing these fields with advanced immunology techniques will shed further light on the ways in which exposure to diverse microbiomes may influence human health.

As with green space, biodiversity can also be characterized in a variety of ways, with important implications. For 
example, bird, mammal, and plant communities respond differently to land-use change, as does the functional versus genetic diversity of those communities (Flynn et al. 2009). As compared with genetic diversity, functional diversity is often more difficult to quantify but may represent a more important indicator; results from analyses of genetic diversity may also be inconsistent with those looking at functional diversity (Flynn et al. 2009). Information on microbial functional diversity should be incorporated into assessments of urban green space characteristics in order to detect whether and how microbial diversity relates to remotely detectable green space attributes like NDVI, leaf area index, and land-cover classifications.

\section{Research gaps and future directions}

In addition to the lack of environmental microbiome-health studies testing the biodiversity hypothesis, we identified a number of other research gaps. Most studies included in our review were conducted in developed nations in temperate regions; clearly, studies are also needed in less developed nations, both because they are currently underrepresented and because these regions are experiencing the most rapid growth in urban populations. We suggest that it is important to understand how climate impacts the ways in which people interact with green spaces in tropical regions, and the consequent effects on human health. The highest rates of urbanization and population growth are expected to occur in sub-Saharan Africa over the next several decades (UN 2014), and therefore a better understanding of the potential for green spaces to buffer adverse effects of the rural-to-urban demographic shift could yield substantial public health returns.

While many of the studies in our sample included measurements of the quantity of green space, primarily obtained from satellite-derived data, few attempted to define green space quality, primarily because it is still unclear what characteristics of green space confer health benefits and therefore constitute factors relating to "quality". Before green spaces can be effectively implemented to improve health, the important characteristics (eg biodiversity, complexity, scale, accessibility) of high-quality spaces need to be elucidated.

In the past there has been negligible cross-disciplinary research that knits biological science and public health together, yet multiple perspectives are required to explore the underlying mechanisms that explain the pathophysiological effects of human exposure to biodiversity. A joint public health-ecology-bioinformatics program of work could provide robust, evidence-based solutions for improving the quality of urban greening policies worldwide, a win-win strategy for both humans and nature.

\section{Conclusions}

The scientific literature on urban green space and public health dates back at least to the 1960s, when a French study drew attention to the protective effects of plants, acting - so it was claimed - through microbiological pathways and via interactions with sulfuric air pollution (Raymond 1963). Since that time, the field has grown to the extent that green space is now linked with more than 20 different categories of health outcomes. But the mechanisms connecting health to green space remain unclear. The biodiversity hypothesis potentially provides a mechanism and a unifying explanation for the diverse health benefits; although we found no direct tests of this hypothesis in the urban green space-health literature, evidence in its favor is mounting from such sources as animal models and epidemiological studies. Experimental studies, including community-level interventions, are needed to identify these mechanisms, including the role of exposure to the diversity of environmental microorganisms found in natural environments.

This systematic review helps define the most important gaps in this field of research and therefore where scientific effort could achieve the greatest gains. Once the mechanisms underlying green space health effects - along with the characteristics, scale, and biological composition of green space that influence human health and ecosystem function - have been identified, urban green spaces can be optimized for public health gains on a global scale.

\section{- References}

Andrusaityte S, Grazuleviciene R, Kudzyte J, et al. 2016. Associations between neighbourhood greenness and asthma in preschool children in Kaunas, Lithuania: a case-control study. BMJ Open 6: e010341.

Aronson MFJ, Lepczyk CA, Evans KL, et al. 2017. Biodiversity in the city: key challenges for urban green space management. Front Ecol Environ 15: 189-96.

Aspinall P, Mavros P, Coyne R, et al. 2015. The urban brain: analysing outdoor physical activity with mobile EEG. Brit J Sport Med 49: $272-76$.

Astell-Burt T, Feng X, and Kolt GS. 2014c. Is neighborhood green space associated with a lower risk of Type 2 diabetes? Evidence from 267,072 Australians. Diabetes Care 37: 197-201.

Astell-Burt T, Feng X, and Kolt GS. 2014b. Neighbourhood green space and the odds of having skin cancer: multilevel evidence of survey data from 267,072 Australians. J Epidemiol Commun H 68 : 370-74.

Astell-Burt T, Mitchell R, and Hartig T. 2014a. The association between green space and mental health varies across the lifecourse. A longitudinal study. J Epidemiol Commun H 68: 578-83.

Bolund P and Hunhammar S. 1999. Ecosystem services in urban areas. Ecol Econ 29: 293-301.

Bortolini L, Cividino SRS, Gubiani R, et al. 2016. Urban green spaces activities: a preparatory groundwork for a safety management system. J Safety Res 56: 75-82.

Burgoine T, Jones AP, Namenek Brouwer RJ, et al. 2015. Associations between BMI and home, school and route environmental expo- 
sures estimated using GPS and GIS: do we see evidence of selective daily mobility bias in children? Int J Health Geogr 14: 8.

Cahenzli J, Köller Y, Wyss M, et al. 2013. Intestinal microbial diversity during early-life colonization shapes long-term IgE levels. Cell Host Microbe 14: 559-70.

Carlsten C and Rider CF. 2017. Traffic-related air pollution and allergic disease: an update in the context of global urbanization. Curr Opin Allergy Cl 17: 85-89.

Dadvand P, Nieuwenhuijsen MJ, Esnaola M, et al. 2015. Green spaces and cognitive development in primary schoolchildren. $P$ Natl Acad Sci USA 112: 7937-42.

Dadvand P, Villanueva CM, Font-Ribera L, et al. 2014. Risks and benefits of green spaces for children: a cross-sectional study of associations with sedentary behavior, obesity, asthma, and allergy. Environ Health Persp 122: 1329-35.

Demuzere M, Orru K, Heidrich O, et al. 2014. Mitigating and adapting to climate change: multi-functional and multi-scale assessment of green urban infrastructure. J Environ Manage 146: 107-15.

Donovan GH, Butry DT, Michael YL, et al. 2013. The relationship between trees and human health: evidence from the spread of the emerald ash borer. Am J Prev Med 44: 139-45.

Ege MJ, Mayer M, Normand A-C, et al. 2011. Exposure to environmental microorganisms and childhood asthma. New Engl J Med 364: 701-09.

Flies EJ, Skelly C, Negi SS, et al. 2017. Biodiverse green spaces: a prescription for global urban health. Front Ecol Environ 15: 510-16.

Flynn DFB, Melanie G-P, Nogeire T, et al. 2009. Loss of functional diversity under land use intensification across multiple taxa. Ecol Lett 12: 22-33.

Fuertes E, Markevych I, von Berg A, et al. 2014. Greenness and allergies: evidence of differential associations in two areas in Germany. J Epidemiol Commun H 68: 787-90.

Fujimura KE, Demoor T, Rauch M, et al. 2014. House dust exposure mediates gut microbiome Lactobacillus enrichment and airway immune defense against allergens and virus infection. P Natl Acad Sci USA 111: 805-10.

Gascon M, Triguero-Mas M, Martinez D, et al. 2015. Mental health benefits of long-term exposure to residential green and blue spaces: a systematic review. Int J Env Res Pub He 12: 4354-79.

Gascon M, Triguero-Mas M, Martinez D, et al. 2016. Residential green spaces and mortality: a systematic review. Environ Int 86: 60-67.

Gifford R. 2007. The consequences of living in high-rise buildings. Archit Sci Rev 50: 2-17.

Halonen JI, Kivimaki M, Pentti J, et al. 2014. Green and blue areas as predictors of overweight and obesity in an 8-year follow-up study. Obesity 22: 1910-17.

Hanski I, von Hertzen L, Fyhrquist N, et al. 2012. Environmental biodiversity, human microbiota, and allergy are interrelated. $P$ Natl Acad Sci USA 109: 8334-39.

Hartig T, Mitchell R, de Vries S, et al. 2014. Nature and health. Annu Rev Publ Health 35: 207-28.

Kuo M. 2015. How might contact with nature promote human health? Promising mechanisms and a possible central pathway. Front Psychol 6: 1093.
Lepczyk CA, Aronson MFJ, Evans KL, et al. 2017. Biodiversity in the city: fundamental questions for understanding the ecology of urban green spaces for biodiversity conservation. BioScience 67: 799-807.

Maki-Opas TE, Borodulin K, Valkeinen H, et al. 2016. The contribution of travel-related urban zones, cycling and pedestrian networks and green space to commuting physical activity among adults - a cross-sectional population-based study using geographical information systems. BMC Public Health 16: 760.

Mitchell R and Popham F. 2007. Greenspace, urbanity and health: relationships in England. J Epidemiol Commun H 61: 681-83.

Mulder IE, Schmidt B, Stokes CR, et al. 2009. Environmentallyacquired bacteria influence microbial diversity and natural innate immune responses at gut surfaces. BMC Biol 7: 79.

Nelson AE and Forbes AA. 2014. Urban land use decouples plantherbivore-parasitoid interactions at multiple spatial scales. PLoS ONE 9: e102127.

Nielsen AB, van den Bosch M, Maruthaveeran S, et al. 2014. Species richness in urban parks and its drivers: a review of empirical evidence. Urban Ecosyst 17: 305-27.

Piao S, Yin G, Tan J, et al. 2015. Detection and attribution of vegetation greening trend in China over the last 30 years. Glob Change Biol 21: 1601-09.

Qian H and Ricklefs RE. 2007. A latitudinal gradient in large-scale beta diversity for vascular plants in North America. Ecol Lett 10: 737-44.

Raymond V. 1963. The role of green spaces in the prevention of infectious diseases of the respiratory tract. Rev Hyg Med Soc 11: 239-42.

Richardson EA, Mitchell R, Hartig T, et al. 2012. Green cities and health: a question of scale? J Epidemiol Commun H 66: 160-65.

Riedler J, Braun-Fahrländer C, Eder W, et al. 2001. Exposure to farming in early life and development of asthma and allergy: a crosssectional survey. Lancet 358: 1129-33.

Rook GAW. 2013. Regulation of the immune system by biodiversity from the natural environment: an ecosystem service essential to health. P Natl Acad Sci USA 110: 18360-67.

Rook GAW, Raison CL, and Lowry CA. 2014. Microbial "old friends", immunoregulation and socioeconomic status. Clin Exp Immunol 177: $1-12$.

Ruokolainen L, von Hertzen L, Fyhrquist N, et al. 2015. Green areas around homes reduce atopic sensitization in children. Allergy 70: 195-202.

South EC, Kondo MC, Cheney RA, et al. 2015. Neighborhood blight, stress, and health: a walking trial of urban greening and ambulatory heart rate. Am J Public Health 105: 909-13.

Threlfall CG, Mata L, Mackie JA, et al. 2017. Increasing biodiversity in urban green spaces through simple vegetation interventions. $J$ Appl Ecol 54: 1874-83.

Triguero-Mas M, Dadvand P, Cirach M, et al. 2015. Natural outdoor environments and mental and physical health: relationships and mechanisms. Environ Int 77: 35-41.

UN (United Nations). 2014. World urbanization prospects: the 2014 revision. New York, NY: UN. 
von Hertzen L, Beutler B, Bienenstock J, et al. 2015. Helsinki alert of biodiversity and health. Ann Med 47: 218-25.

Wheeler BW, Lovell R, Higgins SL, et al. 2015. Beyond greenspace: an ecological study of population general health and indicators of natural environment type and quality. Int J Health Geogr 14: 17.

Wolf LJ, zu Ermgassen S, Balmford A, et al. 2017. Is variety the spice of life? An experimental investigation into the effects of species richness on self-reported mental well-being. PLOS ONE 12: $\mathrm{e} 0170225$.
Zhang J, Wu J, and Liu Y. 2016. Polycyclic aromatic hydrocarbons in urban green spaces of Beijing: concentration, spatial distribution and risk assessment. Environ Monit Assess 188: 511.

\section{Supporting Information}

Additional, web-only material may be found in the online version of this article at http://onlinelibrary.wiley.com/doi/10. 1002/fee.2077/suppinfo

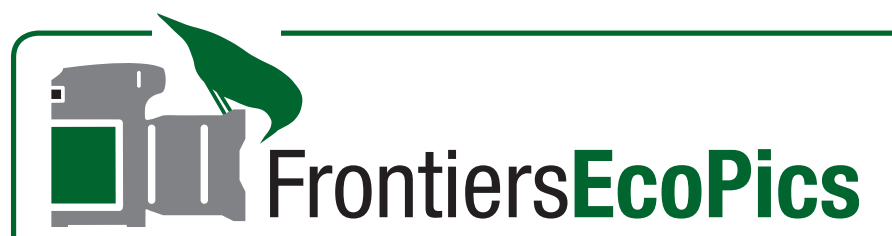

\section{Casual encounter?}

0 the banks of Limoncocha Lake, in Amazonian Ecuador, Megalomyrmex incisus ants seemed indifferent to the presence of a large, colorful, spiny, nymphalid caterpillar Catonephele acontius devouring

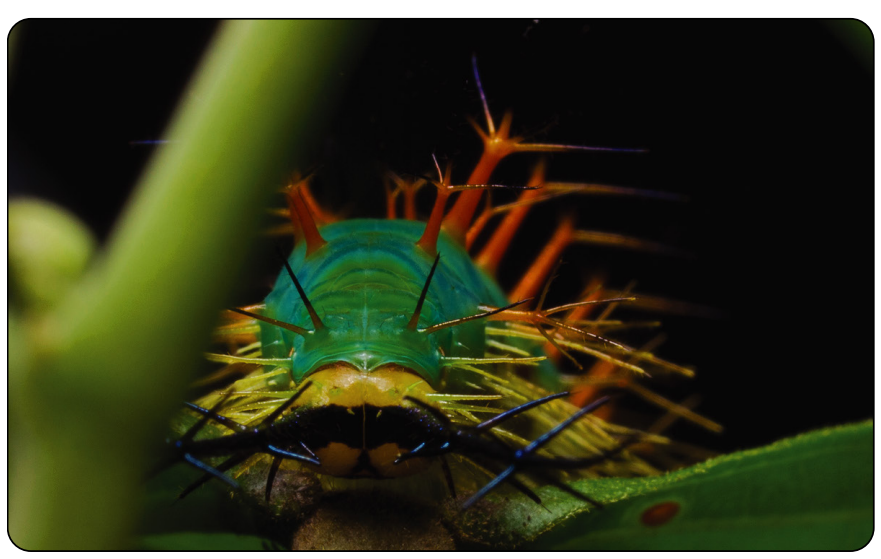

the leaves of an Alchornea glandulosa sapling. This plant species secretes extra floral nectar through specialized glands at the base of its leaves. This secretion is considered an indirect defense mechanism because it can attract the natural enemies of herbivores, including ants (Ecology 1978; doi.org/10.2307/1938771). The presence of these typically soil-residing ants on A glandulosa saplings suggests that they don't forage exclusively at the leaf-litter layer level but that they also sometimes gather nectar from plants. Surprisingly, during these observations, $M$ incisus never attacked the caterpillar. If two herbivores ants and caterpillars - are both obtaining large amounts of nutrients from the plant, a few simple questions arise: who is favored in the long term, and how? Or was this just a chance encounter? What kind of chemical (ie cyanide typically secreted by this Euphorbiaceae plant) or other signals do these nymphalid caterpillars use to avoid or manipulate ants? This is important, given that, unlike some other caterpillar species (eg many lycaenids), they lack dorsal nectar organs that provide ants with sugary secretions - a known mutualism between certain caterpillars and ants, which, in turn, protects the plant from other herbivores. Finally, is this an ant-plant mutualism in the making, or an example of an ant cheating the system?

Rafael E Cárdenas

Pontifical Catholic University of Ecuador, Quito, Ecuador doi:10.1002/fee.2095

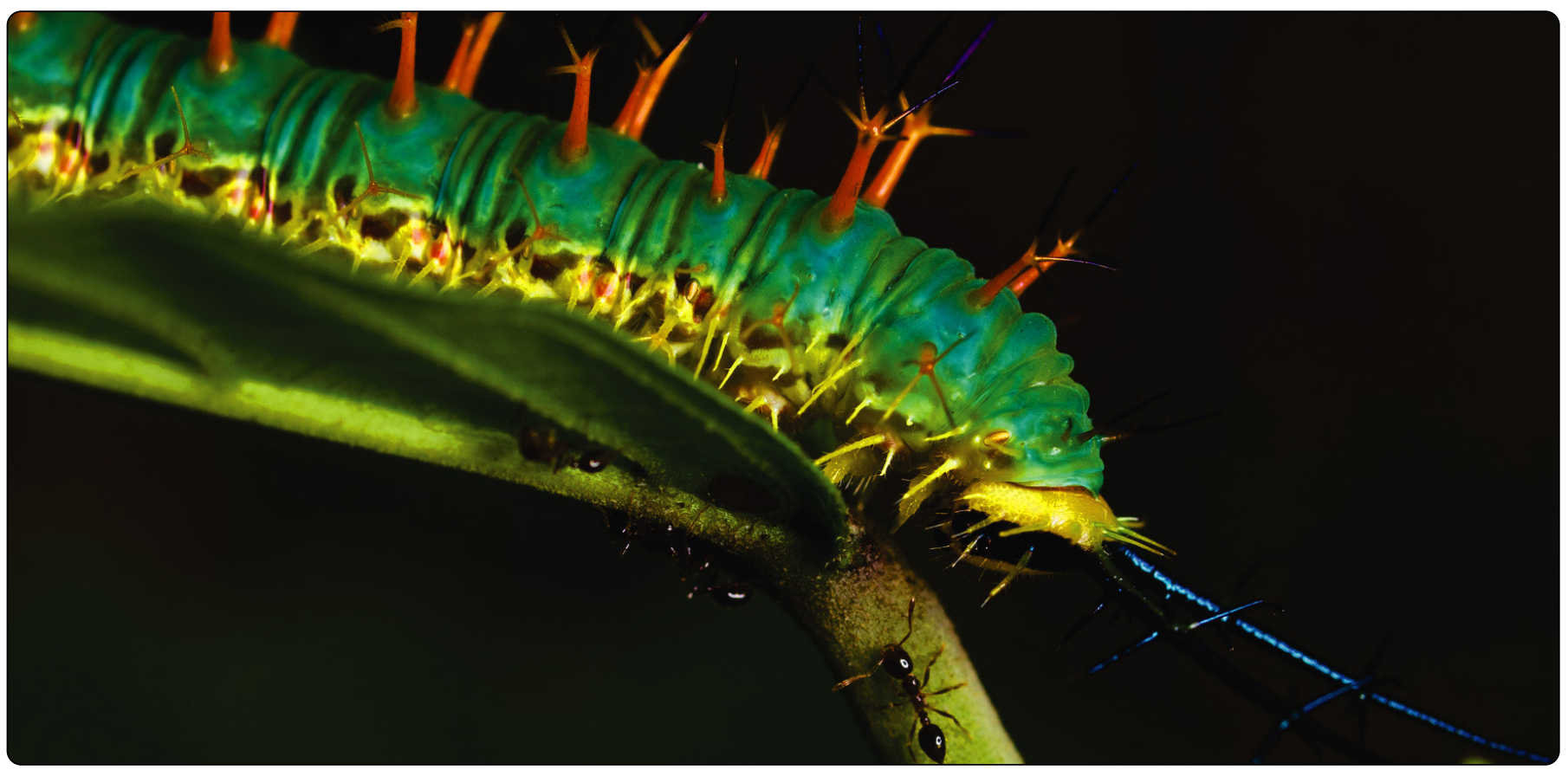

